\title{
Кристаллические дефекты в фотопреобразователях, полученных методом термомиграции
}

\author{
(C) В.Н. Лозовский ${ }^{1}$, А.А. Ломов ${ }^{2}$, Л.С. Лунин ${ }^{1}$, Б.М. Середин ${ }^{1}$, Ю.М. Чесноков ${ }^{3}$ \\ ${ }^{1}$ Южно-Российский государственный политехнический университет (НПИ) им. М.И. Платова, \\ 346428 Новочеркасск, Россия \\ ${ }^{2}$ Физико-технологический институт Российской академии наук, \\ 117218 Москва, Россия \\ ${ }^{3}$ Национальный исследовательский центр „Курчатовский институт“, \\ 123182 Москва, Россия \\ E-mail: seredinboris@gmail.com
}

(Получена 12 апреля 2016 г. Принята к печати 20 апреля 2016 г.)

\begin{abstract}
Приводятся результаты исследований кристаллической структуры областей кремния, перекристаллизованных в процессе термомиграции жидкой кремний-алюминиевой зоной. Подобные области, легированные акцепторной примесью, необходимы для получения высоковольтных фотопреобразователей.

С помощью рентгеновских дифракционных методов двухкристальных кривых отражения и топографии, а также просвечивающей электронной микроскопии высокого разрешения установлено, что при проведении термомиграции жидких зон в виде серии тонких полос или прямоугольных сеток формируются монокристаллические области. Выявлены дислокационные полупетли, которые лежат в поверхностных слоях лицевой и тыльной сторон подложки. В перекристаллизованных областях обнаружены $\{311\}$-дефекты.
\end{abstract}

DOI: $10.21883 / F T P .2017 .03 .44196 .8264$

\section{1. Введение}

Одним из перспективных направлений повышения эффективности фотопреобразования солнечного излучения на кремнии является использование концентраторных модулей [1]. В этом случае фотопреобразователь изготавливается в виде кремниевой матрицы из микроминиатюрных последовательно соединенных фотоэлементов с $p$-n-переходами на гранях, перпендикулярных рабочей поверхности кристалла [2]. Основная трудность в получения такой матрицы заключается в организации локального легирования протяженных чередующихся каналов, пронизывающих всю толщу кремниевой пластины (рис. 1).

Использование диффузионного легирования для этих целей нецелесообразно, как из-за размытия границы между основным кристаллом и обогащенной примесью областью, так и из-за большой длительности процесса создания каналов толщиной в сотни микрон. Оба этих фактора не позволяют достичь требуемой миниатюризации элементов в плоскости подложек и как следствие высоких заявленных значений эффективности высоковольтного фотопреобразования.

Альтернативным способом получения таких областей может быть метод термомиграции [3,4], позволяющий получать $p-n$-переходы с резкими границами перпендикулярно поверхности подложки на всю ее толщину. Процесс термомиграции заключается в последовательной перекристаллизации кристаллического тела жидкой зоной растворителя, движущейся под действием градиента температуры [5].

На рис. 2 показана фотография, демонстрирующая возможности термомиграции жидкой зоны на основе алюминия для перекристаллизации кремниевой пластины [6,7]. Эксперименты [2] по использованию термомиграции для изготовления областей матричных преобразователей энергии подтвердили принципиальную возможность ее применения. Однако приборы, созданные на основе этого метода, не показали расчетной эффективности. Одной из причин этого может являться наличие структурных дефектов рабочих областей матрицы, которые, являясь ловушками для свободных носителей зарядов, могут приводить к изменению энергетических уровней в зонной структуре. Если планарным гетероструктурам посвящено достаточно большое количество исследований в этой области, то работы, посвященные совершенству структуры термомиграционных $p-n$-переходов и ее влиянию на фотовольтаические свойства, ограничены монографией [5]. В частности, в упомянутой работе указывается, что генерация дефектов структуры кристалла может происходить на любой из

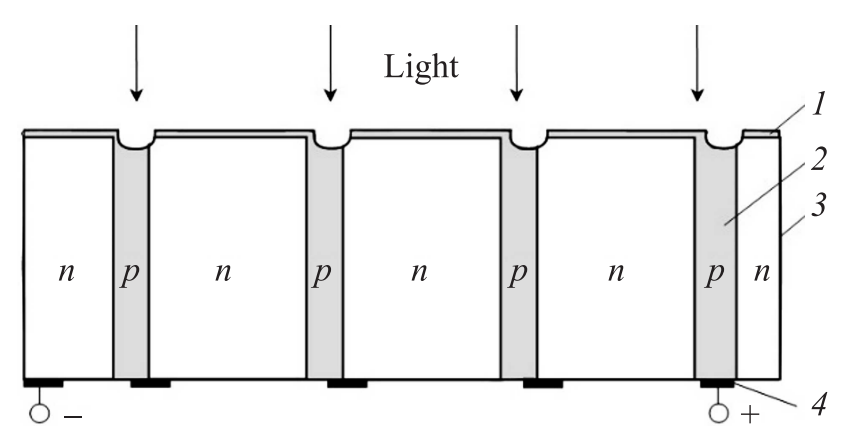

Рис. 1. Схема фотоэлектрического матричного преобразователя: 1 - тонкий диффузионный $p^{+}$-слой, $2-$ разделительная $p^{+}$-область, 3 - исходная $n$-подложка, $4-$ контакты. 


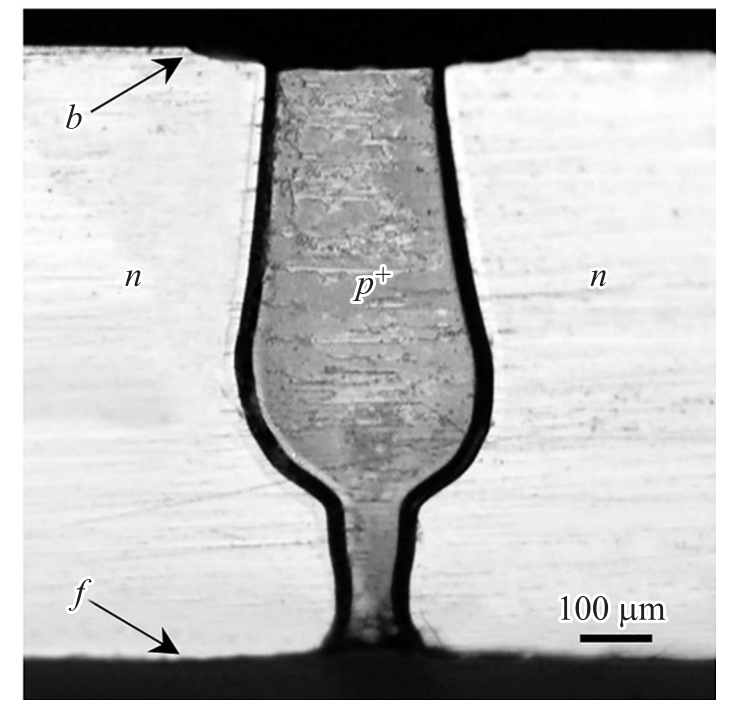

Рис. 2. Фотография микрошлифа вертикального канала, полученного термомиграцией; индексами $f$ и $b$ обозначены фронтальная и тыльная поверхности подложки.

трех стадий метода термомиграции: создания системы зон необходимой топологии, собственно миграции и выхода жидкой зоны на финишную поверхность кристалла. Указанным стадиям соответствуют области перекристаллизованного канала.

Особенностью термомиграции при использовании жидких зон линейной конфигурации является погружение их в кремний без затравки, поэтому роль источника ростового вещества и затравки выполняют различные участки одного и того же кристалла. Характерная глубина залегания дефектной области, при которой завершается образование жидкого включения равновесной формы и происходит полное погружение ее в кристалл, имеет значение, приблизительно равное ее толщине.

Средняя часть термомиграционной области формируется посредством миграции сформированных жидких зон и обусловлена наличием градиента температуры в кристалле. Совершенство этой перекристаллизованной области определяется термическим оборудованием с конфигурацией теплового поля при стремящемся к нулю радиальном градиенте температуры и заданном значении продольного градиента температуры [7].

Процесс миграции атомов вводимой легирующей примеси (растворителя) заканчивается моментом выхода жидкой фазы из кристалла, после которого растворитель, содержащийся в ней, в течение некоторого времени испаряется в пространство термического узла. Во время испарения растворителя происходит кристаллизация пересыщенной ростовым веществом жидкой фазы, в результате чего в финишной части канала формируется кристалл с повышенной дефектностью. Глубина финишной части канала равна примерно половине толщины жидкой зоны.
Как правило, первую область канала, связанную со спорадической кристаллизацией, и третью - финишную, в которой к процессу термомиграции добавляется концентрационное пересыщение кремния из-за испарения алюминия, удаляют двухсторонней механической обработкой. Вторая область - это область стабильного эпитаксиального роста кремния, которую используют для создания матричных фотопреобразователей. В дальнейшем речь идет об этой области канала.

Имеющиеся данные [5] о реальной структуре перекристаллизованных областей получены на основе металлографических методов. Поэтому расширение представлений о реальной структуре областей термомиграционного кремния и формируемого на его основе $p-n$-перехода с привлечением высокоразрешающих структурно-чувствительных методов представляет значительный интерес.

Настоящая работа посвящена исследованию совершенства кристаллической структуры кремниевого элемента матричного преобразователя с вертикальными $p-n$-переходами, полученного термомиграцией, с помощью двухкристальных кривых дифракционного отражения, рентгеновской дифракционной топографии и просвечивающей электронной микроскопии высокого разрешения.

\section{2. Методика эксперимента}

Для проведения исследований использовались монокристаллические пластины кремния марки ЭКЭФ-10 диаметром 60 мм, толщиной 400 мкм, ориентацией по плоскости (111) с углом отклонения от нее не более $3^{\circ}$, плотностью микродефектов не более $10^{2} \mathrm{~cm}^{-2}$. Для приготовления растворителя использовался зонобразующий материал - алюминий А999.

Заданную ширину вертикальных $p^{+}$-областей обеспечивали фотолитографией сплошного слоя $\mathrm{SiO}_{2}$, сформированного на фронтальной поверхности подложки кремния. В слое $\mathrm{SiO}_{2}$ создавали окна шириной 100 мкм с шагом 3 мм, через которые в кристалл погружали жидкие зоны растворителя на основе алюминия и затем выводили их на тыльную поверхность подложки. Жидкие локальные зоны $\mathrm{Al}-\mathrm{Si}$ формировали в вакууме при температуре $800-850^{\circ} \mathrm{C}$. Процесс термомиграции из полученного слоя раствора-расплава проводили в вакууме в диапазоне температур $1050-1200^{\circ}$ C. Градиент температуры был направлен перпендикулярно плоскости (111) кремниевой пластины и составлял $50-100 \mathrm{~K} / \mathrm{cm}$. Типичная скорость миграции зоны в зависимости от температуры процесса имела значения в диапазоне 400-700 мкм в час. Температурно-временной режим подбирали из условий обеспечения конфигурации канала, изображенного на рис. 2. Перед проведением структурных исследований поверхности образцов последовательно подвергались механической обработке и полирующему химическому травлению. 
Двухкристальные кривые дифракционного отражения (КДО) получены на дифрактометре ТРС-1 (СКБ ИКРАН) при использовании рентгеновской трубки с медным анодом. Падающее на образец излучение формировалось щелевым монохроматором с трехкратным отражением $\mathrm{Si}(111)$ и системой щелей с выходными размерами 0.02 и 1 мм в плоскости рассеяния и перпендикулярно ей соответственно. Образец устанавливался так, чтобы полученные $p$-области были параллельны оси вращения гониометра. Выбор участка поверхности образца при записи КДО осуществлялся микрометрическим винтом с дискретностью 40 мкм.

Рентгеновские топограммы в геометрии Лауэ снимались по методу Ланга на установке XRT100 CCM фирмы Rigaku с серебряным анодом $(\lambda=0.56 \AA)$. Дифракционное изображение проецировалось на рентгеновскую фотопленку. Параметр съемки $\mu t=0.36$, где $\mu$ - линейный коэффициент фотоэлектрического поглощения $8 \mathrm{~cm}^{-1}, t-$ толщина образца. Полученные сведения сопоставляли с данными металлографического анализа. Для этого использовалась стандартная методика определения плотности дислокаций в кремнии селективным травителем.

Исследование подложек методом электронной микроскопии проводилось в просвечивающем растровом электронном микроскопе (ПРЭМ) TITAN 8-300 (FEI,CША) с корректором сферической аберрации при ускоряющем напряжении 300 кэВ. Для исследования кристаллов методами ПРЭМ был приготовлен поперечный срез (верхние 5 мкм фронтальной стороны) с помощью фокусированного ионного пучка $\mathrm{Ga}^{+}$в электронно-ионном микроскопе HeliosNanoLab ${ }^{\mathrm{TM}}$ 600i (FEI, CША). Исследования проводились в режимах: светлого и темного полей, электронограмм от выделенной области, ПРЭМ высокого разрешения с использованием высокоуглового кольцевого детектора.

\section{3. Экспериментальные результаты и их обсуждение}

Совершенство структуры каналов и прилегающих к ним областей оценено по КДО. КДО представлены на рис. 3 для фронтальной $(1,2)$, тыльной $(3,4)$ сторон образца и для эталонной подложки (5) кремния. Видно, что кривые $(1,3)$ от участков образца, расположенных между каналами, имеют один максимум, практически совпадающий с максимумом для эталонного кристалла кремния (кривая 5), а на кривых $(2,4)$ от границы область-канал их два. Угловое расстояние между ними для фронтальной и тыльной сторон образца $\Delta \vartheta=18$ и 14 угл. сек. соответственно. Наличие на кривой КДО со стороны меньших углов второго интенсивного и достаточно узкого максимума свидетельствует об образовании кристаллической области - слоя, когерентного с матрицей подложки и увеличенным межплоскостным расстоянием (ковалентные радиусы для $\mathrm{Si}$ и $\mathrm{Al}$

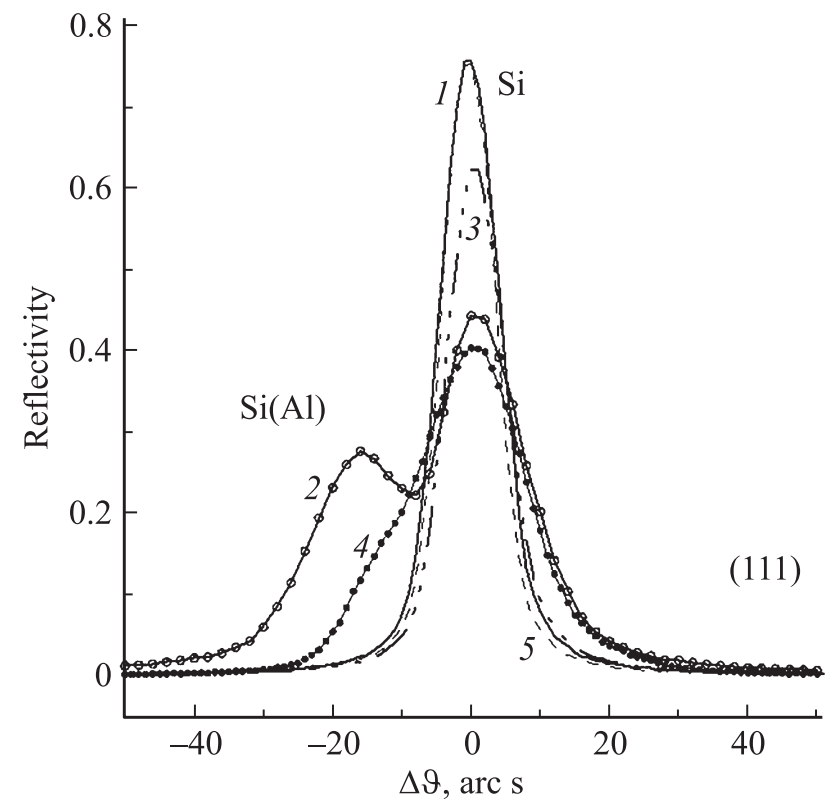

Рис. 3. Экспериментальные кривые дифракционного 111 отражения от фронтальной $(1,2)$ и тыльной $(3,4)$ поверхности $\mathrm{Si}(111)$ подложки после создания в ней термомиграционных каналов, легированных алюминием (см. рис. 2); КДО: 1,3 - от участков $n$-подложки между каналами; $2,4-$ от участков вблизи границы с каналом; 5 - от совершенной подложки кремния.

равны 0.117 и 0.121 нм соответственно) на величину $\Delta d / d \approx(2-3.5) \cdot 10^{-4}$. Результаты эксперимента показывают, что межплоскостное расстояние в легированном алюминием канале увеличено, причем больше с фронтальной стороны образца. Необходимо отметить, что при записи КДО равномерность распределения площади засветки пучка рентгеновского излучения по поверхности образца на границе двух зон не контролировалась. Поэтому сравнение интенсивности максимумов вблизи границы область-канал не может быть характеристикой относительного кристаллического совершенства соответствующих участков образца. Ширины максимумов от легированных алюминием каналов не превосходят двойную ширину КДО от эталонного образца (кривая 5 на рис. 3). Причина уширения КДО обусловлена возможными градиентами деформаций и структурными дефектами на границе двух областей. В целом, по данным КДО (полуширина, максимум рефлекса), структурное совершенство каналов ниже, чем основной матрицы образца. Однако можно утверждать, что канал, несмотря на наличие структурных искажений, является монокристаллом, а его кристаллические плоскости когерентны подложке. Поскольку ширины дифракционных пиков на КДО значительно не уширены, каналы достаточно совершенны по структуре и предположительно не содержат значительного числа дислокаций.

На рис. 4 представлена топограмма части образца с перекристаллизованными зонами в отражении 440. 


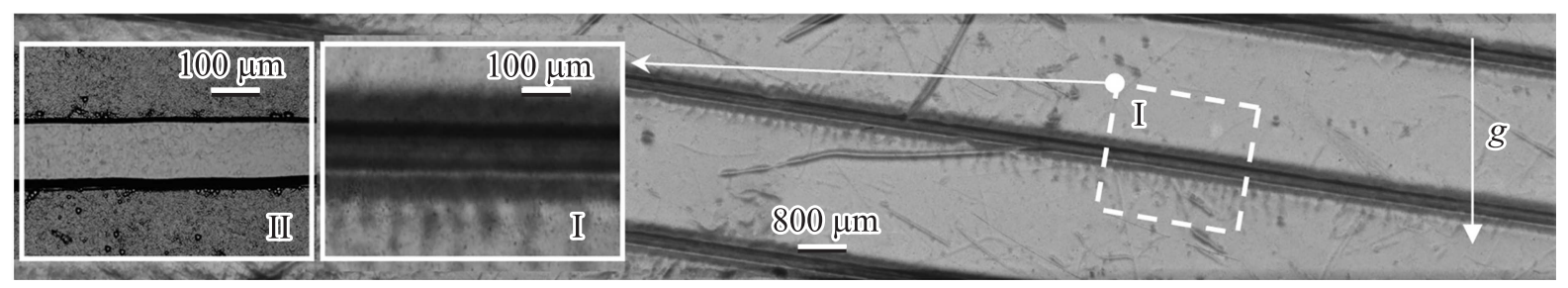

Pис. 4. Топограмма от перекристаллизованного кристалла, полученная по методу Ланга, 440 отражение, $\mathrm{Ag} K_{\alpha 1}$. На вставках приведены увеличенное изображение части топограммы $(I)$ и изображение $(I)$ перекристаллизованной области после выявления дислокаций.

Направление дифракционного вектора g перпендикулярно длинной стороне топограммы. Видно, что у границ каналов в подложке существует значительный градиент напряжений, что проявляется в большой ширине изображения областей кремния, прилегающих к границам каналов. В этих областях возможно образование дислокаций из-за частичной релаксации напряжений на границах. Изображения этих дислокаций на топограммaх частично маскируются изображениями напряжений и выглядят как бахрома. Предположительно бахрому образуют полупетли дислокаций, закрепленные своими двумя концами на границах канала (см. вставку I на рис. 4). Полупетли лежат в поверхностных слоях обеих сторон образца. Их разбег от границы каналов соизмерим с шириной канала.

Такие полупетли не выявляются травителем, за исключением мест их закрепления на границах каналов в виде дислокационных ямок травления, но видны на топограммах, снятых в геометрии прохождения рентгеновских лучей. Сами каналы свободны от дислокаций. Эти факты подтверждаются картинами избирательного

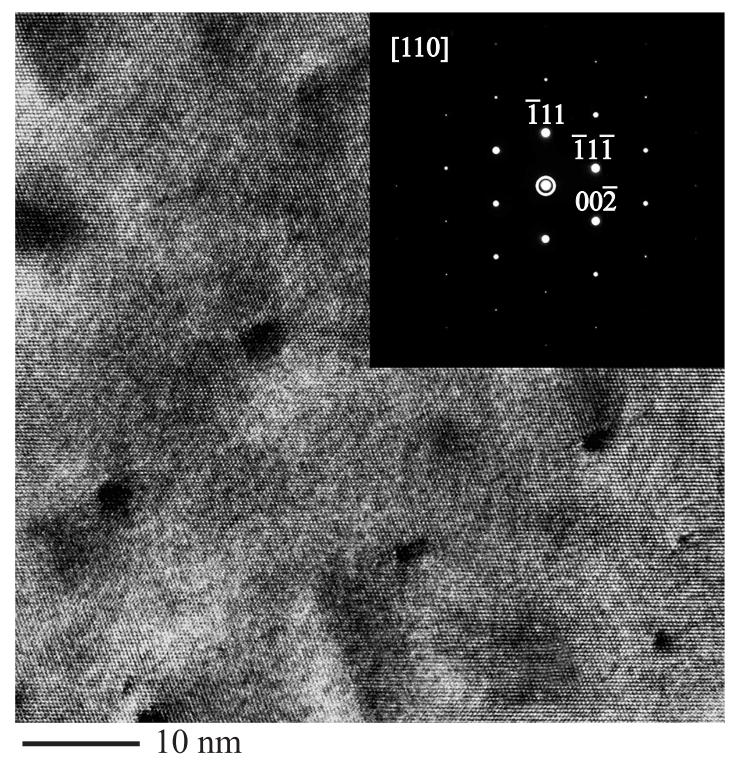

Рис. 5. Электронограмма просвечивающей микроскопии в перекристаллизованной области кристалла. травления двух сторон образца. На вставке II рис. 4 видны скопления дислокаций. Таким образом, выводы, сделанные на основании топографических и дифрактометрических исследований, совпадают.

Дефекты обнаруживаются на электронно-микроскопических картинах прямого разрешения (см. рис. 5). Исследования методом ПРЭМ выявляют отсутствие включений нанокристаллов (фаз) силицида алюминия в монокристалле $\mathrm{Si}$, на что указывает отсутствие особенностей (контраста) на темнопольных ПРЭМ изображениях, а также отсутствие дополнительных рефлексов (пиков) на электроннограмме (см. вставку на рис. 5). На ПЭМ изображениях высокого разрешения поперечного среза в ориентации [110] наблюдаются $\{311\}$-дефекты (см. рис. 6).

Размеры $\{311\}$-дефектов не превышают 15 нм. Концентрация наблюдаемых $\{311\}$-дефектов составляет $(1 \pm 0.5) \cdot 10^{11} \mathrm{~cm}^{-2}$, что соответствует примерно $2 \cdot 10^{16} \mathrm{~cm}^{-3}$. Природа этих дефектов может быть связана как со скоплением атомов растворителя в жидкой зоне (алюминия), так и с термодефектами из-за содержащего-

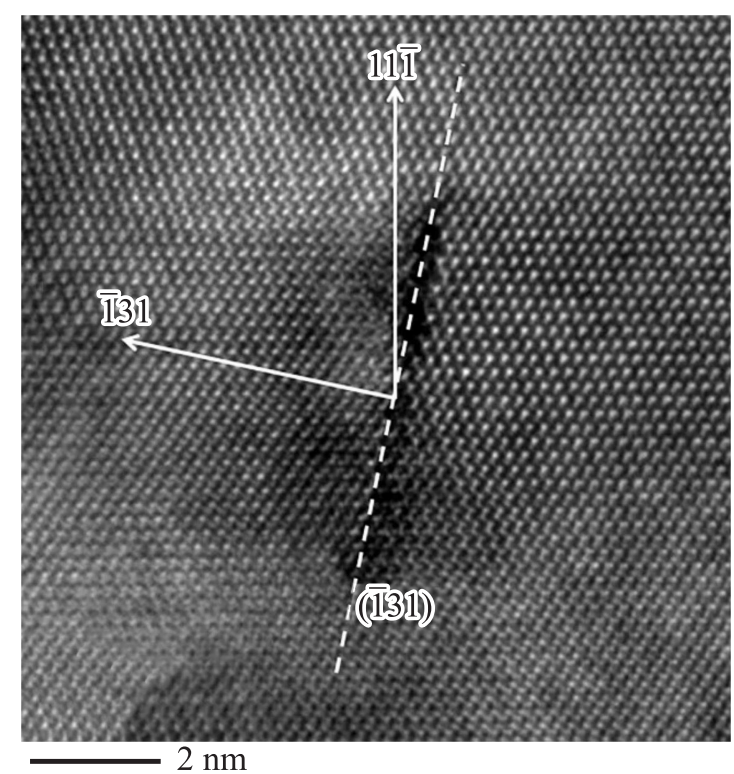

Рис. 6. ПЭМ изображение $\{311\}$-дефекта в перекристаллизованной области. 
ся в матрице кристалла кислорода и других примесей [8]. Для выяснения влияния обнаруженных дефектов на фотопроводимость кремния проводятся дополнительные исследования.

\section{4. Заключение}

На основании совокупности всех представленных результатов исследования можно сделать следующие выводы.

1. Кристаллическая решетка в перекристаллизованных областях, созданных методом термомиграции, является монокристаллической и обладает достаточно высоким структурным совершенством.

2. На границе канал-матрица подложки существует градиент напряжений. В прилегающих к границе областях возможна частичная релаксация напряжений за счет генерации дислокационных полупетель, закрепленных концами на границах каналов. Разбег полупетель от границ каналов в подложку соизмерим с шириной канала.

3. Дислокационные полупетли лежат в поверхностных слоях лицевой и тыльной сторон подложки.

4. Методом ПРЭМ в каналах обнаружены $\{311\}$-дефекты.

5. Термомиграция жидких включений может служить достаточно эффективным методом локального легирования кристаллов электрически активными примесями при сохранении достаточно высокого кристаллического совершенства легированного слоя.

Авторы выражают благодарность С.Ю. Мартюшову за помощь при съемке рентгеновских топограмм и И.Л. Шульпиной за их описание. Работа выполнена в рамках госзадания № 16.4757.2017/БЧ.

\section{Список литературы}

[1] В.М. Андреев, В.А. Грилихес, В.Д. Румянцев. Фотоэлектрическое преобразование концентрированного солнечного излучения (Л., Наука, 1989).

[2] А.П. Ландсман, Д.С. Скребков, В.А. Унишков. ФТТ, 5 (11), 2136 (1971).

[3] В.Г. Дорошенко, М.Б. Закс, В.А. Калашьян, В.Н. Лозовский, Ю.В. Скоков, О.И. Солодуха. Гелиотехника, 4, 14 (1979).

[4] Patent US US3936319. Solar Cell. (1976).

[5] В.Н. Лозовский, Л.С. Лунин, В.П. Попов. Зонная перекристаллизация градиентом температуры полупроводниковых материалов (М., Металлургия, 1987).

[6] В.Н. Лозовский, Л.С. Лунин, Б.М. Середин. Электрон. техн., сер. 2, Полупр. приборы, 2-3 (236), 103 (2015).

[7] В.Н. Лозовский, Б.М. Середин, А.С. Полухин, А.И. Солодовник. Электрон. техн., сер. 2, Полупр. приборы, 5 (239), 65 (2015).

[8] S. Takeda, M. Kohyama, K. Ibe. Philosophical Magazine A. 70 (2), 287 (1994).

Редактор Г.А. Оганесян

\section{Crystal defects in the solar cells obtained by the method of thermomigration}

\author{
V.N. Lozovskij ${ }^{1}$, A.A. Lomov², L.S. Lunin ${ }^{1}$, \\ B.M. Seredin ${ }^{1}$, Yu.M. Chesnokov ${ }^{3}$ \\ ${ }^{1}$ Platov South-Russian State Polytechnic University \\ (NPI), \\ 346428 Novocherkassk, Russia \\ ${ }^{2}$ Institute of Physics and Technology, Russian \\ Academy of Sciences, \\ 117218 Moscow, Russia \\ ${ }^{3}$ National Research Centre „Kurchatov Institute“, \\ 123182 Moscow, Russia
}

\begin{abstract}
The report describes the results of studies of the crystal structure of regions of silicon, recrystallized during the process of thermomigration liquid $\mathrm{Si}-\mathrm{Al}$ zone in the volume of a silicon substrate. Similar regions doped with an acceptor impurity are used to obtain high voltage solar cells.

Using $X$-ray combination-crystal diffraction and topography, as well as high-resolution transmission electron microscopy it was found that during the execution of thermomigration liquid zones on the basis of aluminum as a series of thin strips or rectangular grids single crystal regions can be formed. At the boundary between silicon and $\mathrm{Si}(\mathrm{Al})$ strips the dislocation half-stitches located in the near surface layers of the front and back sides of the substrate were revealed. In recrystallized regions $\{311\}$-type defects were detected.
\end{abstract}

